\title{
IMMUNOLOGICAL EVALUATION OF DIFFERENT IMPLANT ABUTMENT INTERFACES FOR COMPLETE LOWER IMPLANT ASSISTED OVERDENTURE IN CONTROLLED DIABETIC PATIENTS
}

\author{
Faten A.S. Abutaleb* and Hesham S. Borg ${ }^{* *}$
}

\begin{abstract}
Immunological and inflammatory mechanisms perform a key role in the development and progression of type 2 diabetes mellitus. The objective of this study was to evaluate immunologically the effect of different implant abutment interface, the platform switched (PS) and platform matched (PM) implants for implant assisted complete mandibular overdenture in controlled type II diabetic patients.
\end{abstract}

Methodology: Ten edentulous controlled type II diabetic male patients were selected in a split- mouth study design, where group I represented the right side of the patient and restored with platform-switched implant while group II represented the left side of the patient and restored with platform matched implants. The patients received complete mandibular implant assisted overdenture with O-ring attachment. Saliva samples were collected to measure the level of salivary cytokines (TNF- $\alpha$ \& IL-6) using ELISA technique. The recall visits for every patient was at the time of insertion, 3 and 6 months. The data of this study were collected, tabulated and statistically analyzed by IBM-SPSS statistics software.

Results: Comparing from denture insertion for group 1, both cytokines (TNF- $\alpha$ \& IL-6) were significantly increased after 3 months and significantly decreased after six months, but there were insignificant differences in both cytokines from denture insertion up to 6 months. While for group 2 , there a was significant increase from 0 to 3 months and from 0 to 6 months and significant decrease from 3 to 6 months. When comparing the two studied groups regarding the mean level of both pro inflammatory salivary cytokines (TNF- $\alpha \&$ IL-6) after 3 and six months of the new denture delivery, group II levels were significantly higher than group I levels. There were significant differences between both groups. Group I implants represented less mean of TNF- $\alpha$ \& IL-6 levels.

Conclusion: TNF- $\alpha$ and IL- 6 can be used as a site specific marker in monitoring early inflammatory changes in peri-implant sulcular fluid. Platform-Switched dental implant is the implant of choice particularly in controlled type II diabetic patients to control inflammatory changes around implant and avoid progression of type 2 diabetes mellitus.

KEY WARDS: Diabetes mellitus- Platform switching implants- platform matching implants immunological study.

* Assistant Prof of Removable Prosthodontics, Prosthodontic Department, Faculty of Dentistry, Tanta University ** Lecturer of Removable Prosthodontics, Prosthodontic Department, Faculty of Dentistry, October 6 University 


\section{INTRODUCTION}

Diabetes mellitus is a chronic disease described by relative or absolute insulin deficiency and consequent glucose intolerance ${ }^{1}$. Immunological and inflammatory mechanisms play a key role in the evolution and growth of type 2 diabetes mellitus ${ }^{2}$.

Recently, there has been a growing interest in the measurement of cytokines for clinical applications. As cytokines are directly implicated in various pathophysiological conditions in humans, and their increased production is responsible for their elevated levels in different body fluids . Cytokines concentrations can reflect the severity of some diseases and can be markers of prognosis ${ }^{3}$.

It has been documented that the process of bone loss in implant-assisted overdenture is initiated upon abutment connection. Although not fully understood, marginal bone loss has been related to the implant-abutment micro gap and associated microbial contamination ${ }^{4}$. The presence of a microgap at the implant-abutment interface is resulting in bacterial colonization at the implant sulcus and this is the possible etiologic mechanism for marginal bone loss ${ }^{5}$. It is potential that there is bacterial leakage within the implant system, after its prosthetic connection, with subsequent penetration of bacteria and their products within the micro-gap between implant and abutment. This would cause an inflammatory process close to the crestal bone, resulting in bone support loss ${ }^{6,7}$.

In an attempt to reduce marginal bone loss, implant systems have been developed where the outer edge of the implant-abutment interface (micro gap) is moved toward the center of the implant and away from the bone margin. The bacterial induced an inflammatory response is moved to the central axis of the implant away from the marginal bone and is called platform switching ${ }^{8}$. This type of connection moves the perimeter of implant abutment junction (IAJ) to the center of implant axis. It is possible that moving the (IAJ) inward brings out bacteria more internally and, therefore, away from the bone crest; this would explain the limitation in bone resorption $^{9,10}$.

According to Carinci et al ${ }^{11}$ platform switching can be achieved by using abutments with a diameter smaller than the implant neck or body width, by increasing the implant neck diameter with respect to the implant body width, using platform-switched implants and conical emergence abutments and finally using implants with a reverse conical neck referred to as Bone Platform Switching. This embraces an inward bone ring in the coronal part of the implant that is in continuity with the alveolar bone crest.

Gingival crevicular fluid (GCF) is the inflammatory exudates derived from a number of sources including serum, the connective tissue and epithelium through which GCF passes on its way to the gingival crevice. As the fluid traverse the inflamed tissue, enzymes and other molecules as well as products of cell and tissue remodeling and degradation of host and bacterial origin are collected. The cellular components of GCF are 70$80 \%$ neutrophills, $10-20 \%$ monocytes/macrophages, $5 \%$ mast cells and 5\% T-lymphocytes ${ }^{12}$.

Inflammation of the peri-implant area elicits an immune response regulated by the key cytokines (TNF, InerLeukin. $1 \beta$, transforming growth factor$\beta$, Interleukin 6 , Interleukin 10 ) that control the progression and/or suppression or the inflammatory response. Overproduction of pro inflammatory cytokines released by monocytes/macrophages and $\mathrm{T}$ cells in response to microbial challenge can lead to the breakdown of the periodontal or peri-implant tissues ${ }^{13}$.

The measuring techniques of cytokines in the body fluids (blood, saliva, serum and plasma) are bioassay and immunoassay (such as immunoradiometric assay (IRMA) and enzyme-linked immunosorbent assay (ELISA) ${ }^{14}$. 
Despite most clinical studies have reported a positive impact of platform switching on crestal bone stability, yet the data have still been controversial and inconclusive \& up to date the literature still lacks providing clinical evidence about the true influence of platform switching on preserving bone and soft tissue. The purpose of this study was to evaluate and compare immunologically dental implants with different platforms.

\section{MATERIALS AND METHODS}

Ten completely edentulous controlled type II male diabetic patients with average 55 years old presented at the prosthodontic clinic Tanta University were selected for this study. The patients have sufficient inter-arch space to place the endosseous implants and superstructures. All patients with Class I angle's ridge relationship and had old dentures, suffering from poor retention of the mandibular one. The patients must be free from any other metabolic, systemic, and endocrine diseases rather than diabetes. After the patients were informed for the line of treatment and the need for their regular and frequent recall visits, they approved their treatment plan on a written consent to follow the study protocol throughout the total period of the research.

The patients referred to the physician for general check-up and laboratory investigations as Blood glucose level including, Fasting blood glucose level, Post-prandial blood glucose level. A new acrylic conventional complete denture was fabricated and duplicated to make surgical guide stent. Split mouth study design was used, each patient was represented for two groups, group I represented the right side of the patient and group II represented the left side of the patient. Two implants $3.3 \mathrm{~mm}$ diameter and $13 \mathrm{~mm}$ length (Shútz Impla implant system) were placed in the mandibular interforamenal region (figure 1), the right implant is platform switched design (Conical Hybrid Connection Implant) while the left implant is with non-platform switched design
(Dual Surface Conical Screw ImplantShútz Impla German system (ball and socket) was used in this study (figure 2). Three months later after confirmation of ossteointegration (figure 3), the definitive prostheses was constructed for each patient.

\section{Peri-implant crevicular fluid sampling and assay}

To obtain the peri-implant crevicular fluid samples. The site to be sampled was isolated with cotton rolls, a saliva ejector was used and the site was dried in air. Periopaper strips (Oraflow lnc., New York, USA )were inserted into peri-implant crevice carefully until mild resistance was felt, and left for 30 seconds (figure 4). Care was exercised to avoid mechanical injury of the tissues; any strip contaminated with blood was discarded. Paper strips were immediately placed in eppendorf tubes. Each tube with the paper strip was weighted before, and after sample collection for peri-implant fluid volume calculation ${ }^{15}$. Peri-implant crevicular fluid was extracted by centrifugation and all samples were stored at $-30^{\circ} \mathrm{C}$ until they were analyzed. The level of TNF- $\alpha$ was measured using TNF- $\alpha$-ELISA. (TNF- $\alpha$ Elisa kit-96 T, BE55001 - I B L International - Hamburg, Germany) IL-6 was measured using IL-6- ELISA. (IL-6 Elisa kit-96 T, BE53061 - I B L International - Hamburg, Germany). Three measurements were taken for each patient at denture insertion, after three and six months.

The statistical analysis was carried out using Statistical Package for Social Sciences (SPSS Inc., Chicago, IL, version 15.0 for Windows). The continuous data are represented as Mean \pm SD. Normality of quantitative data was checked by measures Kolmogorov Smirnov tests of normality. Data was normally distributed, so t-test was applied for comparison of two groups and ANOVA test to compare the intervals inside the same group. The Tukey's test used to measue the significance. For time related variables, Paired t-test was applied. All statistical tests were two-sided and performed at a significance level of $\alpha=0.05$. The results of this analysis were tabulated and plotted as graphs 


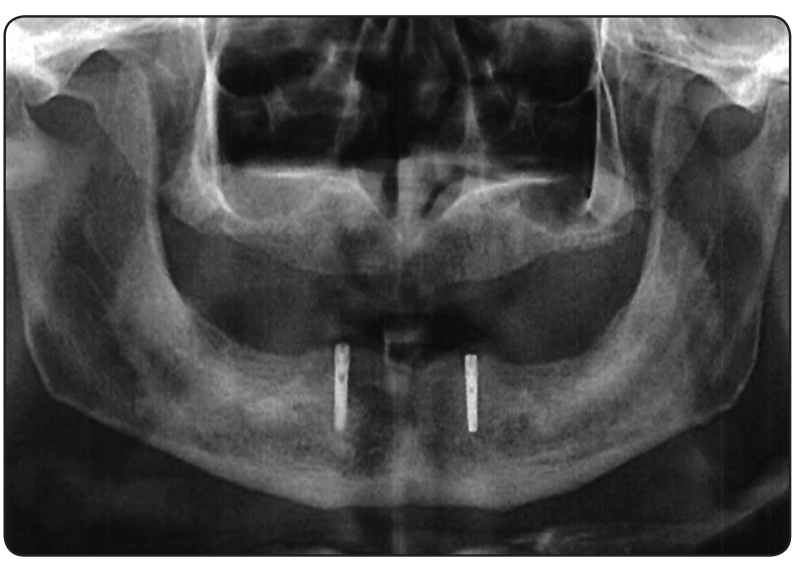

Fig. (1) Panoramic x rays showed the dental implant

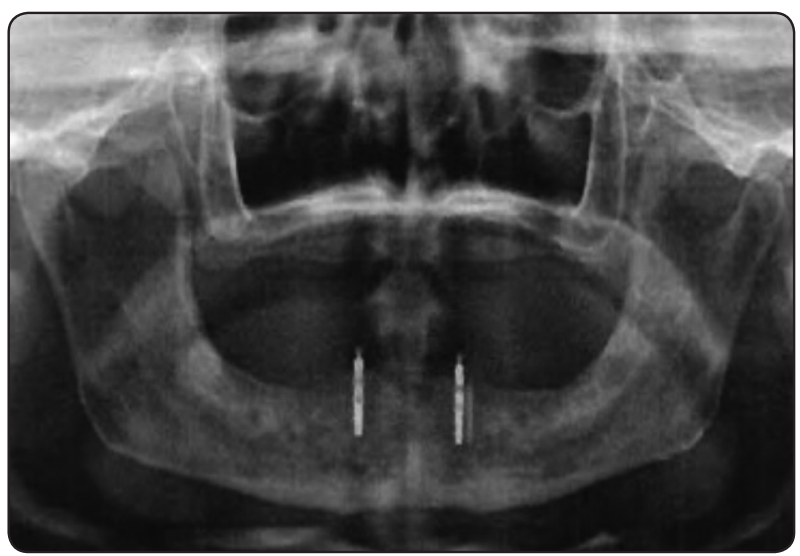

Fig. (3) Panoramic x ray showed the implant with the abutment

\section{RESULTS}

Measuring amount of cytokines (TNF- $\alpha$ ) in saliva as showed in table 1 graph 1

The mean difference of TNF- $\alpha$ level for both groups was significantly increased 3 months after denture insertion and significantly decreased when measured at 6 months. But when comparing the mean difference of TNF- $\alpha$ level from insertion (0 months) versus 6 months there was insignificant difference for group 1 platform switching and significant difference with group 2 platform matching .

When comparing the two groups after 3 months the mean difference was for group I $(4.41 \pm 0.5971)$ and for group $2(5.15 \pm 0.1649)$ there was no

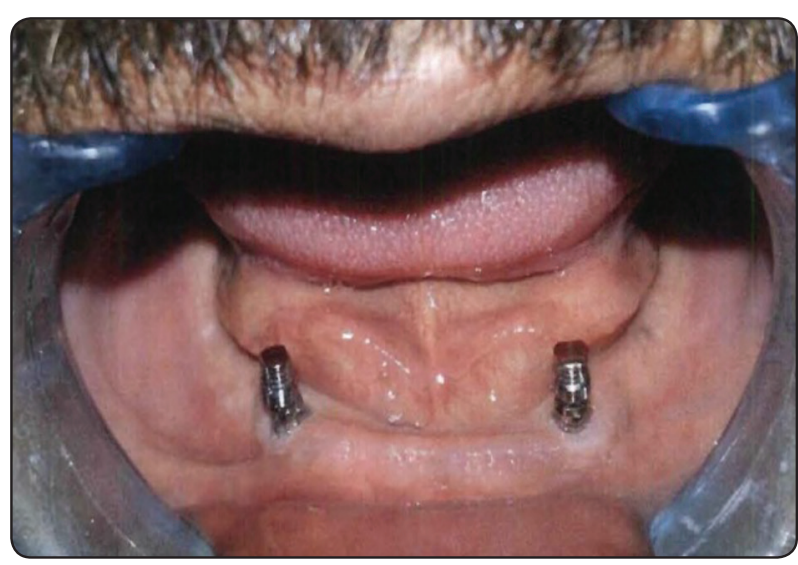

Fig. (2) Metal housing over the abutmen

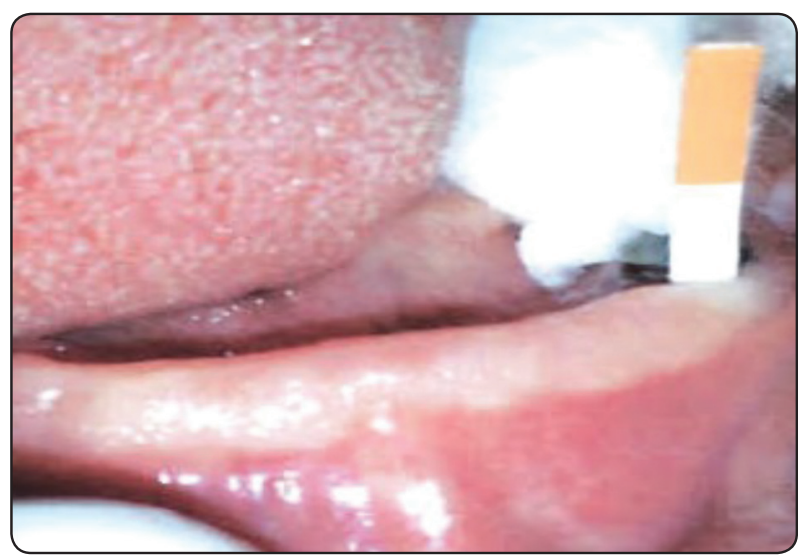

Fig. (4) Collection of peri-implant crevicular fluid with periopaper

significant differences between two groups $(\mathrm{P}>0.05)$

.While after 6 months group 1 was $(3.9 \pm 0.6667)$ and group 2 was $(4.98 \pm 0.5633)$ there was significant differences between two groups $(\mathrm{P}>0.05)$

TABLE (1) showed the mean level of (TNF- $\alpha$ ) in saliva for both groups at follow up period

\begin{tabular}{|c|c|c|c|c|c|}
\hline & \multirow{2}{*}{ Group I } & \multirow{2}{*}{ Group 2} & \multicolumn{2}{|c|}{$\mathrm{T}$ - test } \\
\hline & & & & $\mathrm{T}$ & $\mathrm{P}$ \\
\hline \multicolumn{2}{|c|}{ At insertion } & $3.76 \pm 0.2875$ & $4.48 \pm 0.4467$ & 4.29 & 0.1031 \\
\hline \multicolumn{2}{|c|}{ After 3 monthes } & $4.41 \pm 0.5971$ & $5.15 \pm 0.1649$ & 1.69 & 0.12396 \\
\hline \multicolumn{2}{|c|}{ After 6 monthes } & $3.9 \pm 0.6667$ & $4.98 \pm 0.5633$ & 3.15 & $0.00771 *$ \\
\hline \multirow{2}{*}{ ANNOVA } & $\mathrm{F}$ & 3.97 & 6.69 & & \\
\hline & $\mathrm{P}$ & $0.0308 *$ & $0.004367 *$ & & \\
\hline
\end{tabular}




\begin{tabular}{|c|c|c|}
\hline \multicolumn{3}{|c|}{ Tukey's test for group I } \\
\hline $\begin{array}{c}\text { At insertion \& 3 } \\
\text { months }\end{array}$ & At 3months \& 6 months & $\begin{array}{c}\text { At insertion \&6 } \\
\text { months }\end{array}$ \\
\hline $0.02023^{*}$ & $0.01189^{*}$ & 0.2747 \\
\hline \multicolumn{3}{|c|}{ Tukey's test for group II } \\
\hline $\begin{array}{c}\text { At insertion \& 3 } \\
\text { months }\end{array}$ & At 3months \& 6 months & $\begin{array}{c}\text { At insertion \&6 } \\
\text { months }\end{array}$ \\
\hline $0.003325^{*}$ & $0.002928^{*}$ & $0.04513^{*}$ \\
\hline
\end{tabular}

*Significant, $($ P0.05<).

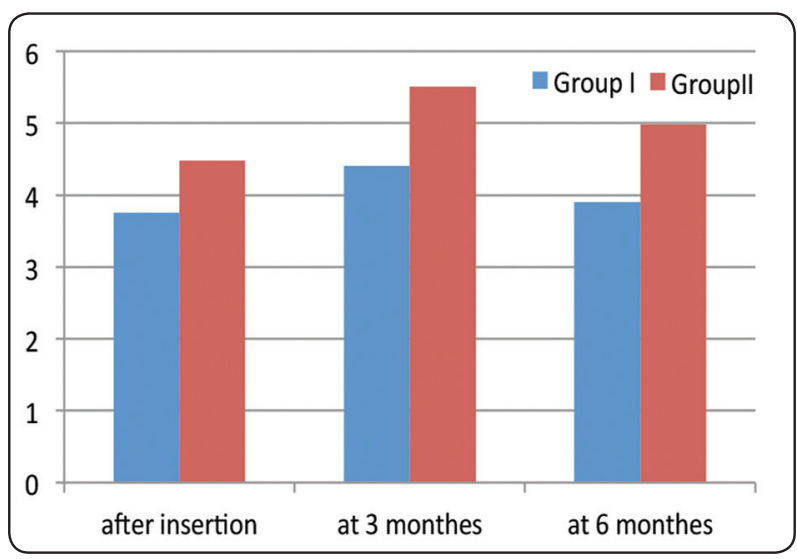

Graph (1) showed the mean level of (TNF- $\alpha)$ in saliva in both groups at follow up period

\section{Measuring amount of cytokines (IL-6) in saliva as showed in table 2 graph 2}

The level of IL-6 for group I and 2 was significantly increased after 3 months and significantly decreased after 6 months but from 0 to 6 months, there was no significant differences for group 1 and a significant differences for group 2.

When comparing the two groups, mean difference and standard deviation was measured after 3 months the data measured was for group I $(3.07 \pm 0.1337)$ and for group $2(3.69 \pm 0.5363)$ there was a significant differences between two groups ( $P>0.05)$. Finally, the data collected and measured after 6 months for group I was $(2.69 \pm 0.1595)$ and for group II was $(3.53 \pm 0.4029)$ there was a significant differences between two groups $(\mathrm{P}>0.05)$
TABLE (2) Showed the mean level of (IL-6) in saliva in both groups at follow up period

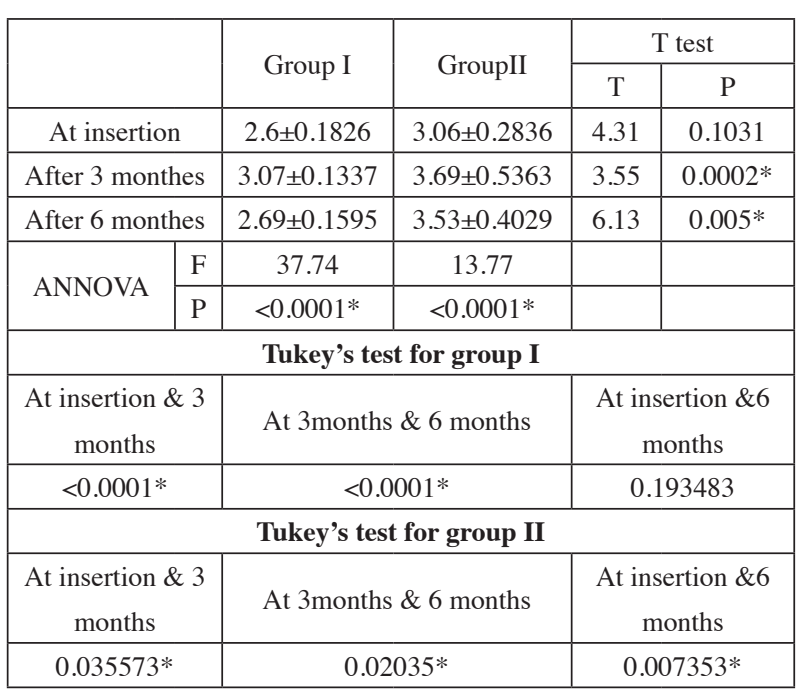

*Significant, $($ P0.05<).

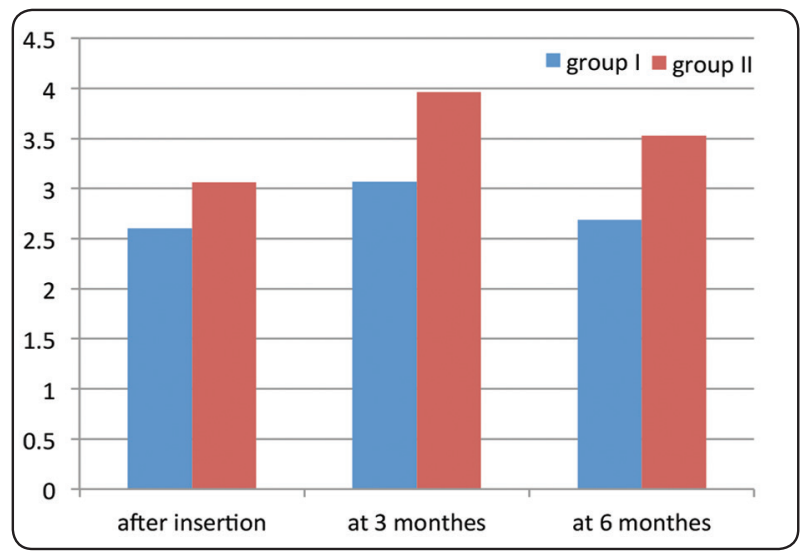

Graph (2) showed the mean level of (IL-6) in saliva in both groups at follow up period

\section{DISCUSSION}

Diabetes mellitus is considered one of the systemic conditions associated with greater risks for implants failure and accelerated bone resorption however; several studies confirmed that, dental implants can be successfully used in controlled type II diabetics.

Implant abutment interface plays a substantial role in providing primary stability and strength to an implant supported restoration. Implant abutment 
interface should ensure optimal load distribution to reduce peak stresses and minimize the infiltration of bacteria and contamination in microgaps ${ }^{16}$.

Platform switching diverts to the use of an abutment joined to an implant neck of larger diameter; studies mentioned that this connection relocates the perimeter of the implant-abutment junction inwards toward the central axis (the middle of the implant) improving the distribution of forces. It was developed to control bone loss after implant placement. Moreover, platform switching is also capable of moving the implant abutment junction and supposedly the inflammatory reaction medially, away from the crestal bone, and thus, preventing crestal bone loss ${ }^{17-19}$.

The need for detecting early inflammatory response, a clinical index usually can only determine the inflammatory response. So the implantologists are focusing on developing site specific tests of higher specifity and sensitivity which may overcome the well-known limitations of traditional measures ${ }^{20}$.

Protein biomarkers and microbial profile from oral fluids could be valuable diagnostic and prognostic tools in the assessment of disease activity around dental implants. This immunologic investigation method provides comprehensive information regarding the current status and prognosis and treatment course of loaded implants as well as the analysis of patient responses to inflammatory disease. By using such information, clinicians can more efficiently determine the treatment plan or take preventive measures ${ }^{21}$.

With assessment of tumour necrosis alpha factor (TNF- $\alpha$ ) and interleukin-6 (IL-6) in the crevicular fluid around healthy implants, implants with peri-implantitis, and healthy teeth. It is found that IL-6 is an important cytokine involved in the regulation of host response to tissue injury and infection $^{22,23}$. TNF- $\alpha$ is a cytokine produced mainly by macrophages. It has been implicated in the periodontal disease process because of its ability to stimulate bone resorption and other catabolic processes $^{24}$.

Absorbent filter paper strips are quick and easy to use, and can be applied to individual sites and, possibly, is the least traumatic when correctly used. The methods of collection may be divided into the intracrevicular (whereas the strip being inserted into the gingival crevice) and the extracrevicular techniques (whereas the strips are overlaid on the gingival crevice region in an attempt to minimize trauma) as reported by Griffths ${ }^{15}$.

The present study was conducted to investigate immunologically the effect of using platformswitched implants in controlled type II completely edentulous diabetic patients receiving implant assisted overdenture. The two dental implant platform showed similar increased level after 3 months of denture insertion but after 6 months ,the pro-inflammatory cytokines were decreased again but insignificantly from baseline for platform switched implant and significantly for platform matched implant. The explanation of these results is the possible exposure of the soft tissues to a portion of the seating platform in the PS or PM group may contribute to higher levels of initial inflammatory response in the initial period. This is in agreement with Petkovic et $\mathrm{al}^{25}$ who reported positive correlation between TNF- $\alpha$ levels and the extent of peri-implant inflammation .

After 6 months ,the cytotoxins level decreased and this is in accordance with Dellavia et $\mathrm{al}^{26}$ who reported that, after prolonged exposure of abutments in the oral cavity, the configuration of the implant abutment interface does not seem to affect the inflammatory cellular and molecular pattern responsible for bone loss. This explain the significant decrease of both cytokines after 6 months .

Disagree with Dellavia et $\mathrm{al}^{26}$ that despite of the presence of micro-gaps at the implant prosthetic connection $^{27}$, the platform switching is allowing less bacterial leakage and less bone $\operatorname{loss}^{28,29}$. This is in accordance with studies that carried with Cochran 
et al and Roet et al ${ }^{30,31}$ and it had been suggested to be related to the establishment of proper physiological-biological dimension ${ }^{32}$.

\section{CONCLUSION}

TNF $\alpha$ and IL-6 and are sensitive markers of inflammation around dental implants. PlatformSwitched dental implant showed less proinflammatory level and is the implant of choice in controlled type II diabetic patients to control inflammatory changes around implant and avoid progression of type 2 diabetes mellitus.

Further clinical studies using biomarkers to monitor the physiological bone remodeling and changes in the microbiome in peri-implant sulcus are still required to help clinicians to make safe and predictable decisions in their clinical practice.

\section{REFERRENCES}

1. Leite-Cavalcanti C, Rodrigues-Gonçalves Md , Rios-Asciutti LS, Leite-Cavalcanti A. The prevalence of chronic disease in a group of elderly Brazilian people and their nutritional status. Rev Salud Publica (Bogota) 2009;11:865877

2. Schwarz V. Inflammation as a factor of the pathogenesis of insulin resistance and type 2 diabetes. Ter Arkh. 2009;81:74-80.

3. Samaranayake L, Essential microbiology for dentistry. 4th ed. Churchill Livingstone; 2012.

4. Weng D, Nagata MJ, Bell M, Bosco AF, de Melo LG, Richter EJ. Influence of microgap location and configuration on the peri-implant bone morphology in submerged implants. An experimental study in dogs. Clin Oral Implants Res. 2008; 19:1141-1147.

5. Park YS, Lee SP, Han CH, Kwon JH, Jung YC. The micro tomographic evaluation of marginal bone resorption of immediately loaded scalloped design implant with various micro thread configurations in canine mandible:pilot study. Oral Implantol. 2010; 36:357-362.

6. Covani U, Marconcini S, Crespi R ,Barone A. Bacterial plaque colonization around dental implant surfaces. Implant Dent. 2006; 15:298-304.
7. Lazzara RJ, Porter SS. Platform switching: a new concept in implant dentistry for controlling post restorative crestal bone levels. Int J Period \& Rest Dent. 2006; 26:9-17.

8. Alkadi L, Wyatt C. Clinical report. Case for implant platform unswitching. J Prosth Dent. 2015; 14:171-173.

9. Calvo-Guirado JL, Ortiz-Ruiz AJ, López-Marí L, DelgadoRuiz R, Maté-Sánchez J, Bravo Gonzalez LA. Immediate maxillary restoration of single-tooth implants using platform switching for crestal bone preservation: a 12-month study. Int J Oral Maxillofac Impl. 2009; 24: 275-281.

10. Canullo L, Fedele GR, Iannello G, Jepsen S. Platform switching and marginal bone-level alterations: the results of a randomized-controlled trial. Clin Oral Implants Res. 2010; 21: 115-121.

11. Carinci F, BrunelliG, Danza M. Platform switching and bone platform switching. J Oral Implantol. 2009; 35:245-250.

12. Champagne CME, Buchanan W, Reddy MS, Preisser JS, Beck JD, Offenbacher S. Potential for gingival crevice fluid measures as predictors of risk for periodontal diseases. Peridontology. 2003; 31:167-180.

13. Tözüm TF, Turkyilmaz I, YamaliKN, Tümer C, Kilinc A, Kilinç K, et al. The effect of delayed versus early loading on nitric Oxide metabolism around dental implants: an 18-months comparative followup study. Int J Oral Maxilloface Implants. 2007;22:53-62.

14. Benyoucef S, Hober D, Shen L, Ajana F, De Groote D, Gérard Y, et al. TNF alpha production by whole blood from HIV-1 infected patients. PatholBiol (Paris). 1996;44:393-396.

15. Griffths GS. Formation, collection, and significance of gingival crevice fluid. Periodontology 2000, 2003;31:32-42.

16. Jain A, Bhat V, Hegde C. Oral Periimplant Bone Loss: Platform Switching or Shifting?-A Review.Int J Recent Sci Res. 2017;85:17239-17241.

17. Baig N, Kadam P, Yeshwante B. Effect of Platform switching on peri-implant tissues: A review J Dent \& Med Sciences. 2015; 14:15-22.

18. Hsu YT, Lin GH, Wang HL.Effects of Platform-Switching on Peri-implant Soft and Hard Tissue Outcomes: A Systematic Review and Meta-analysis. Int J Oral Maxillofac Implants. 2017;32: 9-24.

19. Singla S, Rathee M, Kumar L, Gupta M. Platform switching: A step away from the gap. Europ J Prosth. 2015; 3: $1-9$. 
20. Greenstein G. Contemporary interpretation of probing depth assessments: Diagnostic and therapeutic indications. J Periodontol. 1996; 68:1194-1205.

21. Sesma N, Pazmino CG, Zanardi PR, Chun EP, Laganá DC: Assessment of Marginal Bone Loss around PlatformMatched and Platform-Switched Implants - A Prospective Study .Braz Dent J.2016; 27 : 1760-1806.

22. Yaghobee1 S, Khorsand A, Ghohroudi AR, Sanjari K, Kadkhodazadeh M . Assessment of interleukin-1beta and interleukin-6 in the crevicular fluid around healthy implants, implants with peri-implantitis, and healthy teeth: a cross-sectional study. Korean J Assoc Oral Maxillofac Surg 2014;40:220-224.

23. Wilson M, Reddi K, Henderson B. Cytokine-inducing components of periodontopathogenic bacteria. J Periodontal Res. 1996; 31:393-407.

24. Tatakis DN, Kumar PS. Etiology and pathogenesis of periodontal diseases. Dent Clin North Am. 2005; 49:491-516.

25. Petkovic AB, Matic SM, Stamatovic NV, Vojvodić DV, Todorović TM, Lazić ZR. Pro inflammatory cytokines (IL-1beta and TNFalpha) and chemokines (IL-8 and MIP1alpha) as markers of periimplant tissue condition. Int $\mathbf{J}$ Oral Maxillofac Surg. 2010; 39:478-485.

26. Dellavia C, Canullo L, Allievi C, Lang NP, Pellegrini G. Soft tissue surrounding switched platform implants: an immunohistochemical evaluation. Clin. Oral Impl. Res. 24, 2013, 63-70

27. Tsuge, T, Hagiwara, Y., Matsumura, H. Marginal fit and microgaps of implant-abutment interface with internal antirotation configuration. Dental Materials Journal . 2008; 27: 29-34.

28. Tesmer, M , Wallet S, Koutouzis T , Lund-gren T. Bacterial colonization of the den-al implant fixture-abutment interface: an in vitro study. Journal of Periodontology.2009; 80: 199 -208.

29. Assenza B , Tripodi D , Scarano A , Perroti V , Piattelli A, Iezzi, G, D’Ercole, S. Bacterial leakage in implants with different implant-abutment connections: an in vitro study. Journal of Periodontology.3012; 83: 491-497.

30. Cochran DL, Nummikoski PV, Schoolfield JD, Jones AA, Oates TW. A prospective multicenter 5-year radiographic evaluation of crestal bone levels over time in 596 dental implants placed in 192 patients. Journal of Periodontology .2009;80: 725-733.

31. Roet P, Kan JY, Rungcharassaeng K, Lozada J L, Kleinman AS, Goodacre C J. et al. Immediate loading of unsplinted implants in the anterior mandible for overdentures: a case series. International Journal of Oral Maxillofac Implants.2010;25: 1028-1035.

32. Hartman G.A. \& Cochran, D.L. Initial implant position determines the magnitude of crestal bone remodeling. Journal of periodontology.2004;75: 572-577. 